\title{
Autoeficácia, estratégias de coping e os efeitos das relações interpessoais e organizacionais de discentes de Ciências Contábeis
}

\author{
RESUMO
}

Esta pesquisa busca verificar a influência da autoeficácia nas estratégias de coping mediada pelas relações interpessoais e organizacionais estabelecidas por discentes de Ciências Contábeis. Para tal, a pesquisa descritiva com abordagem quantitativa tem como amostra 311 discentes de Instituições de Ensino Superior Público e Privado, localizadas no estado do Paraná (Brasil), e matriculados no ano de 2018. A partir da técnica de Modelagem de Equações Estruturais (MEE) foi possível constatar que as relações interpessoais e organizacionais atuam como mediadoras da autoeficácia académica com estratégias de coping voltadas para a recusa e distração. Estes resultados ilustram que reconhecer a posição mediadora do relacionamento interpessoal e organizacional entre a autoeficácia e as estratégias de coping é oportuno, na medida em que são constructos ligados ao processo de superação das adversidades vivenciadas no ensino superior. Os resultados indicam que, ao fomentar relações interpessoais e organizacionais satisfatórias, é maximizada a capacidade do discente de enfrentar os problemas de forma mais direta. Essa habilidade torna-se importante, pois contribui para o amadurecimento do discente e para o desenvolvimento de capacidades de enfrentamento adequadas para as situações vivenciadas no ambiente socioacadémico.

Palavras-chave: Autoeficácia; Estratégias de coping; Discentes de contabilidade; Educação contábil.

\section{INTRODUÇÃO}

Os desafios que permeiam a adaptação ao ensino superior e à vida adulta exigem do indivíduo maturidade emocional e adaptabilidade às novas formas de estabelecer relações interpessoais e lidar com as mudanças nos âmbitos académico, social, pessoal, institucional e vocacional (Byrne et al., 2014; Carlotto et al., 2015). As expectativas dos estudantes quanto ao apoio e estrutura organizacional fornecidos pelas Instituições de Ensino Superior

\author{
Alison Martins Meurer ${ }^{i}$ \\ Universidade Federal \\ do Paraná, Brasil \\ lago França Lopes ${ }^{\text {ii }}$ \\ Universidade Federal \\ do Paraná, Brasil \\ Romualdo Douglas \\ Colauto ${ }^{\text {ii }}$ \\ Universidade Federal \\ do Paraná, Brasil
}


(IES) desempenham papel importante na manutenção do discente no ensino superior e para a superação dos desafios da trajetória universitária (Teixeira et al., 2008).

Nesse contexto, a Teoria Social Cognitiva (TSC) preconizada por Bandura (1977; 1982) afirma que o comportamento do indivíduo é direcionado por suas crenças nas habilidades de superar determinados desafios. Essas crenças são denominadas de autoeficácia, que é consubstanciada na perceção que a pessoa tem sobre a sua capacidade de exercer influência e lidar com situações que afetam sua vida (Bandura, 1994). As crenças de autoeficácia têm sido apontadas como um dos principais influenciadores do comportamento humano (Ambiel \& Noronha, 2012) e seu estudo requer a análise e adaptação ao contexto estudado (Bandura, 1997). Estendendo essas considerações ao ambiente universitário, a autoeficácia tem sido definida como "as crenças de um estudante em sua capacidade em organizar e executar cursos de ações requeridos para produzir certas realizações, referentes aos aspetos compreendidos pelas tarefas académicas pertinentes ao ensino superior" (Polydoro \& Guerreiro-Casanova, 2010, p. 268).

Na literatura, há uma corrente que investiga o relacionamento da autoeficácia com as estratégias de coping, que são reações de enfrentamento para minimizar ameaças de danos ou perdas físicas ou psicológicas frente a situações de estresse (Gloria \& Steinhardt, 2016). As estratégias de coping são essenciais para superar adversidades, problemas e alcançar o sucesso na trajetória dos discentes. 0 seu estudo fornece evidências para reconhecer a forma como os jovens se adaptam à realidade do ensino superior, identificar dificuldades vivenciadas e fornecer apoio social e psicológico no decorrer de sua formação (Teixeira et al., 2008).

Embora os estudos precedentes tenham abordado a autoeficácia e/ ou as estratégias de coping em diversas populações e contextos (Barcelos, 2010; Capelo \& Pocinho, 2016; Correia, 2010; Gloria \& Steinhardt, 2016; Guerreiro-Casanova \& Polydoro, 2011), ainda existe campo teórico-empírico a ser explorado junto a estudantes universitários ingressantes no nível de graduação. Evidências obtidas por Teixeira et al. (2008) apontaram que é essencial que o aluno esteja inserido num ambiente universitário que ofereça apoio organizacional e relações interpessoais satisfatórias.

Estendendo essas considerações à área Contábil, tem-se que o perfil dos discentes é comummente marcado pela dupla jornada, na qual estes desempenham as suas atividades profissionais e académicas de modo simultâneo (Peleias et al., 2017). Essa agenda de atividades pode ter efeitos stressantes, visto que estudos (e. g. Silva et al., 2015; Peleias et al., 2017) apontaram que uma parcela significativa dos estudantes e profissionais contábeis brasileiros apresentam elevados níveis de stress. Perante tais situações, acredita-se fortemente que os discentes tendem a manifestar diferentes estratégias de coping, devido à necessidade de equilibrar a jornada dupla, a qual por vezes perfaz todo o período da graduação.

Outras discussões foram direcionadas para a forma como esse cenário stressante pode afetar aspetos da vida universitária na área de Ciências Contábeis, a exemplo do desempenho académico dos estudantes (Silva, 2017) e da evasão do curso (Durso, 2015). Nesta investigação direciona-se a atenção 
para os aspetos relacionais do ambiente académico, em termos de relações interpessoais, seja com colegas, professores ou colaboradores das instituições de ensino, bem como elementos organizacionais das IES, como programas de apoio institucional e oportunidades de desenvolvimento pessoal.

Este estudo é guiado pela seguinte inquietação: qual a influência da autoeficácia nas estratégias de coping mediada pelas relações interpessoais e organizacionais praticadas por discentes de Ciências Contábeis? Consequentemente, o objetivo do estudo consiste em verificar o papel interveniente das relações interpessoais e organizacionais praticadas por discentes de Ciências Contábeis na relação entre as crenças de autoeficácia e estratégias de coping.

As estratégias de coping podem influenciar a trajetória académica dos discentes (Carlotto et al., 2015), auxiliando na identificação de problemas enfrentados pelos alunos com intuito de contribuir com a superação dos desafios no ensino. Tanto a temática de autoeficácia como de estratégias de coping carecem de estudos (Ambiel \& Noronha, 2012; Carlotto et al., 2015; Moreira et al., 2018) que auxiliem a compreender o comportamento dos discentes. Restringindo à área Contábil, as pesquisas são ainda mais escassas (Byrne et al., 2014). Com esta pesquisa, almeja-se auxiliar no desenvolvimento de ações universitárias que possam contribuir para o aprimoramento do ambiente de ensino-aprendizagem, à medida que destaca as relações interpessoais e organizacionais como protagonistas da relação estabelecida entre variáveis comportamentais, como autoeficácia e estratégias de coping.

Para tanto, este estudo considera para análise 311 alunos de instituições públicas e privadas, e as perceções dos mesmos em relação a estratégias de coping, crenças de autoeficácia e relacionamentos desenvolvidos no ambiente socioacadémico foram tratados a partir de uma Modelagem de Equações Estruturais pelos passos preconizados por Baron e Kenny (1986), o que permite vislumbrar o papel interveniente dos relacionamentos desenvolvidos.

\section{AUTOEFICÁCIA}

A Teoria Social Cognitiva (TSC) sustenta que o indivíduo interage e se desenvolve a partir de situações cotidianas e de forma intencional, sendo a autoeficácia um dos seus principais elementos, juntamente com a agência humana, que enfoca no engajamento e alcance dos resultados a partir da ação humana (Bandura, 1977; Pajares, 2018). Para Bandura (1993), o pensamento molda a maioria das ações de uma pessoa, cada curso de ação é desenhado em cenários que visam antecipar as consequências de cada atitude. As pessoas que possuem elevados níveis de crenças de autoeficácia visualizam cenários de sucesso, arriscam-se mais e possuem suporte psicológico para o seu desempenho. Por outro lado, aqueles com baixas crenças de autoeficácia focam-se em possibilidades de erros, devido a inseguranças quanto à sua capacidade e reações aversivas que efetivamente prejudicam seus resultados.

No ambiente académico, a autoeficácia tem-se mostrado capaz de afetar a motivação de estudantes universitários (Duarte \& Faria, 2016), a adaptação ao ensino superior (Fernandes, 2011) e o desempenho académico 
(Loricchio \& Leite, 2012). Bandura (1993, p. 119) argumenta que "pessoas com o mesmo conhecimento e habilidades podem ter desempenho deficiente, adequado ou extraordinário, dependendo das flutuações na capacidade de autoeficácia”. Assim, tal elemento mostra-se relevante na trajetória de discentes.

Polydoro e Guerreiro-Casanova (2010) construíram e validaram um instrumento de pesquisa capaz de mensurar a autoeficácia na formação de estudantes do nível de graduação. Os resultados indicaram a existência de cinco dimensões de autoeficácia: Autoeficácia Académica, Autoeficácia na Interação Social, Autoeficácia na Regulação da Formação, Autoeficácia em Ações Proativas e Autoeficácia na Gestão Acadêmica. A Figura 1 descreve cada dimensão.

Figura 1

Dimensões da Autoeficácia na Formação Superior

\begin{tabular}{|c|c|}
\hline Dimensão & Descrição \\
\hline Autoeficácia Acadêmica & $\begin{array}{l}\text { Avalia a percepção dos estudantes sobre a confiança na capacidade de } \\
\text { aprender, demonstrar e aplicar o conteúdo do curso. }\end{array}$ \\
\hline $\begin{array}{l}\text { Autoeficácia na } \\
\text { Interação Social }\end{array}$ & $\begin{array}{l}\text { Avalia a percepção dos estudantes sobre a confiança na capacidade de } \\
\text { relacionar-se com os colegas e professores com fins acadêmicos e } \\
\text { sociais. }\end{array}$ \\
\hline $\begin{array}{c}\text { Autoeficácia na } \\
\text { Regulação da Formação }\end{array}$ & $\begin{array}{l}\text { Reflete a percepção na confiança na própria capacidade de estabelecer } \\
\text { metas, fazer escolhas, planejar e autorregular suas ações no processo de } \\
\text { formação e desenvolvimento de carreira. }\end{array}$ \\
\hline $\begin{array}{c}\text { Autoeficácia em ações } \\
\text { Proativas }\end{array}$ & $\begin{array}{l}\text { Destina-se à identificação da confiança percebida na capacidade de } \\
\text { aproveitar as oportunidades de formação, atualizar os conhecimentos e } \\
\text { promover melhorias institucionais. }\end{array}$ \\
\hline $\begin{array}{l}\text { Autoeficácia na Gestão } \\
\text { Acadêmica }\end{array}$ & $\begin{array}{l}\text { Refere-se a confiança percebida na capacidade de envolver-se, planejar } \\
\text { e cumprir prazos em relação às atividades acadêmicas. }\end{array}$ \\
\hline
\end{tabular}

Fonte: Elaborado com base em Polydoro \& Guerreiro-Casanova (2010).

A partir das dimensões de Autoeficácia na Formação Superior pode-se delinear a configuração das convicções dos universitários para a realização de uma tarefa no ambiente socioacadémico, facto que proporciona auxiliar ações académicas, intervenções dos docentes e elaboração de projetos que fomentem tais crenças nos alunos (Polydoro \& Guerreiro-Casanova, 2010).

Byrne et al. (2014) investigaram a autoeficácia de ingressantes no curso de Contabilidade e Finanças de uma universidade irlandesa. As evidências apontaram que parcela significativa dos discentes possuem baixo nível de autoeficácia. Houve diferenças entre géneros, sendo o grupo masculino aquele com menor nível de autoeficácia. Alguns dos resultados indicaram que mais de $40 \%$ dos estudantes não tinham confiança para responder a perguntas relacionadas ao conteúdo, mesmo em ambientes de tutoria. Além disso, entre $45 \%$ a $50 \%$ dos discentes não eram confiantes sobre sua capacidade de elaborar um plano de estudos e planear o seu tempo de modo adequado. A partir dos resultados, sugere-se que haja mais proatividade das IES e dos docentes a fim de incentivar os discentes a desenvolverem os seus níveis de autoeficácia.

Matos (2014) investigou a autoeficácia de estudantes brasileiros dos cursos de Administração e Ciências Contábeis. Os resultados ilustram que estudantes que frequentam o ensino superior na capital possuem níveis mais elevados de autoeficácia em comparação aos do interior, mostrando a 
influência do ambiente de ensino sobre os discentes. Níveis mais elevados de autoeficácia também contribuem para melhorar o desempenho académico, sendo um fator a ser explorado pelas IES.

Satchakova (2018) avaliou a associação da autoeficácia com características pessoais e a participação em programas de formação para a inserção no mercado de trabalho junto a estudantes do curso de Contabilidade de duas universidades australianas. Entre os resultados, verificou-se que características como género e idade não estão associadas a autoeficácia, enquanto ser aluno internacional ou estudar a tempo parcial está ligado a maiores níveis de persistência. As implicações do estudo pontuam a necessidade de formar discentes assertivos, dispostos a enfrentar desafios de modo confiante e com postura crítica, sendo a autoeficácia um dos elementos a ser aprimorado neste processo.

Tepper e Yourstone (2018) investigaram variáveis não cognitivas que afetam o desempenho de discentes do curso de Contabilidade. Os resultados suportam que a autoeficácia está relacionada com melhor desempenho académico. Dessa forma, pontua-se a relevância de analisar demais fatores que são influenciados pela autoeficácia e que podem interferir na trajetória discente. Desse modo, almeja-se expandir as discussões ao analisar as estratégias de coping como consequente dos níveis de autoeficácia.

\section{MODELO TEÓRICO DA PESQUISA}

Lazarus e Folkman (1984) definem coping como "mudanças constantes nos esforços, cognitivos e comportamentais, utilizado pelos indivíduos com objetivo de lidar com demandas específicas, internas ou externas, que são avaliadas como sobrecarregando ou excedendo seus recursos pessoais" (Lazarus \& Folkman, 1984, p. 141). 0 coping está ligado diretamente ao stress, visto que é a reação ou o modo como o organismo enfrenta situações stressantes (Costa \& Leal, 2006; Pocinho \& Capelo, 2009), sendo que o stress é caracterizado como um processo no qual o indivíduo avalia as suas capacidades como inferiores às demandas exigidas pela situação (Lazarus \& Folkman, 1984).

Especificamente no ensino superior, Costa e Leal (2006) propuseram um instrumento de pesquisa, no qual categorizam as estratégias de coping em cinco dimensões, conforme a Figura 2. 
Figura 2

Dimensões das Estratégias de Coping no Ensino Superior

\begin{tabular}{|c|l|}
\hline Dimensão & \multicolumn{1}{|c|}{ Descrição } \\
\hline \multirow{5}{*}{ Controle } & $\begin{array}{l}\text { Implica o autocontrole da situação (resistir ao impulso de fazer juízos } \\
\text { irrefletidos, e de tomar decisões precipitadas; ter tempo para agir), a } \\
\text { coordenação dos comportamentos ou atividades (traçar objetivos, fazer } \\
\text { um plano, tratar o problema de forma abstrata e lógica) e a contenção } \\
\text { das emoções (não entrar em pânico, não mostrar aos outros as emoções } \\
\text { que vivenciam). }\end{array}$ \\
\hline Suporte Social & $\begin{array}{l}\text { Abrange o pedido, desejo ou necessidade de ajuda em termos } \\
\text { cooperativos (de trabalho conjunto), cognitivos (pedido de conselhos e } \\
\text { informações) e afetivos (necessidade de escuta, reconhecimento ou } \\
\text { alento). }\end{array}$ \\
\hline Retraimento & $\begin{array}{l}\text { Implica uma tendência para se isolar do mundo exterior (afastamento } \\
\text { social), um esforço para não pensar no problema (refugiando-se no } \\
\text { imaginário ou no sonho) ou ter dificuldades em descrever suas emoções } \\
\text { e sentimentos (alexitimia). }\end{array}$ \\
\hline Distração ou Recusa & $\begin{array}{l}\text { Significa agir como se o problema não existisse, desenvolver atividades } \\
\text { para se distrair ou “esquecer" o problema. }\end{array}$ \\
\hline \multirow{5}{*}{ Conversão e Aditividade } & $\begin{array}{l}\text { Engloba a mudança, a nível dos comportamentos (em função do } \\
\text { problema) ou das posições cognitivas (que permitam aceitar a situação } \\
\text { ou aprender a viver com ela), a centralização nas formas de resolver o } \\
\text { problema, após analisá-lo, e ainda a adoção de comportamentos de } \\
\text { compensação (drogas, medicamentos, tabaco). }\end{array}$ \\
\hline
\end{tabular}

Fonte: Elaborado com base em Costa e Leal (2006).

Várias investigações buscaram abordar a relação entre autoeficácia e estratégias de coping em diferentes amostras (e. g. Crego et al., 2016; Devonport \& Lane, 2006; Hsieh et al., 2012; Pocinho \& Capelo, 2009). Devonport e Lane (2006) identificaram uma relação positiva entre autoeficácia e estratégias de coping, admitindo a hipótese de uma relação de dualidade, na qual maiores níveis de autoeficácia colaboram para a utilização de estratégias de coping ativas e a utilização destas estratégias maximizam a autoeficácia.

Pocinho e Capelo (2009) encontraram associação significativa entre algumas dimensões de autoeficácia e estratégias de coping adotadas por professores portugueses, indicando que as crenças de autoeficácia potencializam a noção do indivíduo sobre o seu comportamento em situações adversas.

Hsieh et al. (2012) abordaram a autoeficácia e as estratégias de coping, em conjunto com outras variáveis comportamentais, para identificar a influência no desempenho de estudantes de graduação. Os resultados identificaram relação significativa entre ambas variáveis, e que estas afetam o rendimento académico dos discentes. Nesse sentido, há necessidade de os educadores implementarem estratégias que maximizem a autoeficácia dos discentes e os auxiliem a desenvolver estratégias de coping adequadas aos desafios universitários.

Crego et al. (2016) verificaram junto a discentes de graduação que as estratégias de coping caracterizadas por aspetos emocionais estão negativamente associadas ao nível de autoeficácia, enquanto as estratégias de coping com aspetos racionais estão associadas positivamente à autoeficácia. Os autores sugerem a promoção do uso de estratégias de enfrentamento focadas na resolução de problemas e no apoio social, na medida em que as estratégias focadas em emoções fomentam o stress discente. 
Desse modo, acredita-se haver relação entre os níveis de autoeficácia e as estratégias de coping adotadas pelos discentes. Ademais, esses relacionamentos são desenvolvidos num contexto que é afetado pela convivência estabelecida com amigos, professores e colaboradores, e que podem ser fortalecidos ou enfraquecidos a partir da identificação e da satisfação do estudante com a IES. Assim, a atenção direcionada para as instituições de ensino é importante, pois estas figuram como suporte às decisões e às estratégias de coping adotadas pelos discentes em momentos desafiadores no ambiente acadêmico (Costa \& Leal, 2006; Oliveira et al., 2014). Tais relações são formadas a partir do contexto que o discente vivencia. Essas relações interpessoais e organizacionais têm sido associadas as estratégias de coping e a adaptação e vivência no ensino superior (Carlotto et al., 2015).

Crego et al. (2016) sugerem que o apoio social, por meio de relações interpessoais, e as relações organizacionais do discente com a instituição de ensino sejam explorados, visto que estes elementos são capazes de influenciar os níveis de autoeficácia e as estratégias de coping. Tal facto é justificado na medida em que "a percepção de disponibilidade do suporte social, tem um importante valor como protetora do impacto do stress na saúde" (Costa \& Leal, 2006, p. 191). Logo, o modo como os estudantes enfrentam os problemas pode ser conduzido pelas relações estabelecidas com os demais indivíduos e com o ambiente organizacional no qual as atividades académicas são desempenhadas, e possuem também como antecedentes as crenças de autoeficácia, sendo capazes de interferir nas estratégias de coping.

As relações interpessoais e organizacionais apresentam-se como suporte e apoio às decisões dos estudantes. Um ambiente harmonioso, capaz de desenvolver as habilidades sociais dos discentes, tende a direcionar a forma como os problemas são enfrentados (Carlotto et al., 2015). Desse modo, é importante que essas relações sejam observadas pelas IES e sejam aprimoradas dentro do contexto da cultura organizacional, considerando os seus efeitos sobre a relação entre autoeficácia e estratégias de coping dos discentes.

Sob a lente da Teoria Social Cognitiva é preconizado que as crenças de autoeficácia estão ligadas ao ambiente no qual o indivíduo está inserido. No campo académico, a autoeficácia tem sido relacionada ao comportamento dos indivíduos frente a situações stressantes (Crego et al., 2016; Devonport \& Lane, 2006; Hsieh et al., 2012; Pocinho \& Capelo, 2009). Por sua vez, as relações interpessoais e organizacionais estão associadas à autoeficácia e às estratégias de coping adotadas neste ambiente (Carlotto et al., 2015; Costa \& Leal, 2006; Crego et al., 2016; Guerreiro-Casanova \& Polydoro, 2011; Oliveira et al., 2014). Desse modo, propõe-se a seguinte hipótese de pesquisa: as relações interpessoais e organizacionais medeiam a relação entre a autoeficácia e as estratégias de coping dos discentes de Ciências Contábeis.

Com base na hipótese acima, ilustra-se na Figura 33 o modelo teórico proposto. 
Figura 3

Modelo teórico da pesquisa

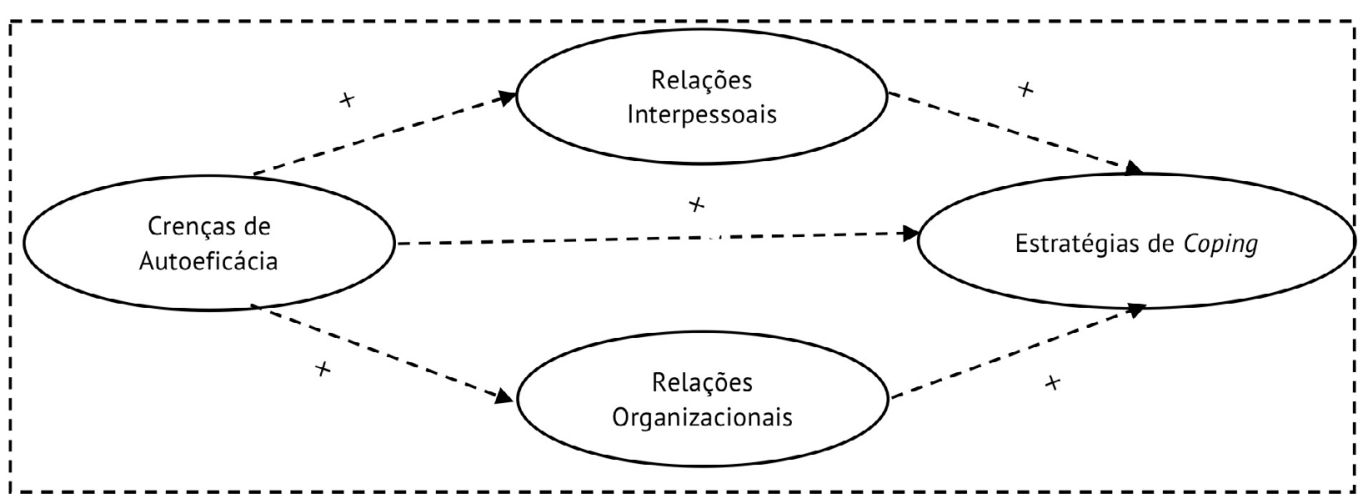

Fonte: Elaborado pelos autores.

A partir da Figura 3, é defendido que a autoeficácia relaciona-se positivamente com as estratégias de coping, sendo que as relações interpessoais e organizacionais medeiam essa relação. Destaca-se que as relações interpessoais e relações organizacionais são analisadas a partir da satisfação dos discentes com esses elementos.

\section{METODOLOGIA}

A pesquisa caracteriza-se como descritiva com abordagem quantitativa. A instrumentalização da pesquisa foi realizada por meio de um questionário (survey) aplicado in loco nos meses de outubro e novembro de 2018. Os dados foram recolhidos junto a discentes matriculados, no ano de 2018, em cursos de Ciências Contábeis de uma IES pública e outra privada, ambas localizadas no estado do Paraná (Brasil).

O questionário foi composto por quatro blocos. Inicialmente foi apresentado o Termo de Consentimento Livre e Esclarecido para que o respondente tivesse conhecimento dos riscos e benefícios da pesquisa, seguindo as diretrizes da Resolução 510 de 07 de abril de 2016 do Comitê Nacional de Saúde. No primeiro, foi mensurada a autoeficácia universitária a partir da adaptação da Escala de Autoeficácia na Formação Superior, de Polydoro e GuerreiroCasanova (2010), sendo utilizadas as dimensões de Autoeficácia Académica, Autoeficácia em Ações Proativas e Autoeficácia na Gestão Académica. Após submeter o instrumento a duas rondas de validação - realizadas por cinco pesquisadores da área de Educação em Contabilidade e pelos coordenadores dos cursos que compuseram a população da pesquisa - algumas afirmações foram excluídas por apresentarem significado dúbio. Além disso, as afirmações foram modificadas do modo interrogativo para o modo afirmativo com o intuito de aproximar o respondente do instrumento de pesquisa, conforme pré-teste.

O segundo bloco destinou-se a identificar a satisfação com as relações interpessoais e organizacionais, composto por 18 afirmações elaboradas a partir de Schleich, Polydoro e Santos (2006). 0 terceiro bloco estava direcionado para a mensuração das estratégias de coping adotadas quanto 
a problemas e obstáculos no ambiente universitário, a partir de 32 afirmações desenvolvidas por Costa e Leal (2006). Tais afirmações constituem-se nas dimensões de Controle, Distração e Recusa, Suporte Social, Retraimento, Conversão e Aditividade. As escalas possuem intervalo de 1 a 10 pontos.

0 quarto bloco possibilitou delinear a caracterização dos 311 respondentes, conforme a Tabela 1 .

Tabela 1

Perfil da Amostra

\begin{tabular}{|c|c|c|c|c|c|}
\hline Gênero & $\mathbf{F}$ & $\%$ & Período & $\mathbf{F}$ & $\%$ \\
\hline Feminino & 161 & 51,77 & $1^{\circ} / 2^{\circ}$ semestre & 125 & 40,19 \\
\hline Masculino & 149 & 47,91 & $3 \% / 4^{\circ}$ semestre & 101 & 32,48 \\
\hline Agênero ou Não-binário & 1 & 0,32 & $5 \% 6^{\circ}$ semestre & 77 & 24,76 \\
\hline Prefiro não responder & 0 & 0,00 & $7^{\circ} / 8^{\circ}$ semestre & 8 & 2,57 \\
\hline Idade* & $\mathbf{F}$ & $\%$ & Instituição de Ensino Superior & $\mathbf{F}$ & $\%$ \\
\hline Parte 1: de 17 anos até 19 anos & 80 & 25,72 & Pública & 224 & 72,02 \\
\hline Parte 2: de 20 anos até 21 anos & 87 & 27,97 & Privada & 87 & 27,98 \\
\hline Parte 3: de 22 anos até 25 anos & 78 & 25,08 & & & \\
\hline Parte 4: de 26 anos até 47 anos & 66 & 21,22 & & & \\
\hline
\end{tabular}

Nota: $f=$ Frequência; $\%$ = percentual.

Fonte: Dados da pesquisa.

A maioria dos respondentes identificaram-se com o género feminino; frequentam maioritariamente os dois primeiros semestres do curso de Ciências Contábeis; têm entre 20 e 21 anos; e consubstanciam o corpo discente de uma IES Pública. A análise estatística foi realizada por meio do software $R$ Studio ${ }^{\circledR}$ utilizando Modelagem de Equações Estruturais (MEE) - PLS-PM (Parcial Least Squares Path Modeling).

A partir dos indicadores definidos no protocolo de análise (ver Figura 4), verificou-se a necessidade de exclusão de algumas afirmações por não apresentarem indicadores satisfatórios na formação dos constructos. 
Figura 4

Protocolo de Análise

\begin{tabular}{|c|c|c|c|c|}
\hline & Etapa & Objetivo & Parâmetro & Referência \\
\hline \multirow{6}{*}{ 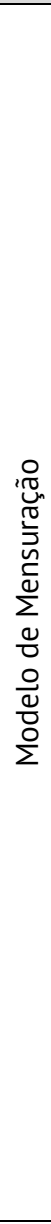 } & DG. Rho & \multirow{3}{*}{$\begin{array}{l}\text { Avaliar a confiabilidade } \\
\text { e capacidade de } \\
\text { agrupamento interno do } \\
\text { construto. }\end{array}$} & Valores acima de 0,7. & \multirow{6}{*}{$\begin{array}{l}\text { Henseler et al. } \\
\text { (2009), Sanchez } \\
\text { (2013), Hair Jr. Et } \\
\text { al. (2014), } \\
\text { Henseler et al. } \\
\text { (2009) e Ringle et } \\
\text { al. (2014). }\end{array}$} \\
\hline & $1^{\circ}$ Autovalor & & Valores acima de 1. & \\
\hline & $2^{\circ}$ Autovalor & & Valores abaixo de 1. & \\
\hline & $\begin{array}{c}\text { Índice de } \\
\text { redundância } \\
\text { (mean_redundancy) }\end{array}$ & $\begin{array}{l}\text { Refletir a capacidade de } \\
\text { um conjunto de } \\
\text { variáveis latentes } \\
\text { independentes para } \\
\text { explicar a variação na } \\
\text { variável latente } \\
\text { dependente. }\end{array}$ & Não há. & \\
\hline & $\begin{array}{c}\text { Cargas fatoriais } \\
\text { (loadings) e cargas } \\
\text { fatoriais cruzadas } \\
\text { (crossloadings) }\end{array}$ & $\begin{array}{l}\text { Avaliar a independência } \\
\text { das variáveis latentes } \\
\text { observadas em relação } \\
\text { as demais. }\end{array}$ & $\begin{array}{l}\text { Para os loadings são } \\
\text { preferíveis valores } \\
\text { acima de } 0,70 . \\
\text { As crossloadings } \\
\text { devem ser maiores } \\
\text { em seus respectivos } \\
\text { fatores. }\end{array}$ & \\
\hline & $\begin{array}{l}\text { Variância Média } \\
\text { Explicada (VME) }\end{array}$ & $\begin{array}{l}\text { Analisar a porção dos } \\
\text { dados } \\
\text { que é explicada por } \\
\text { cada um dos } \\
\text { constructos, respectivos } \\
\text { aos seus conjuntos de } \\
\text { variáveis ou quanto, em } \\
\text { média, as variáveis se } \\
\text { correlacionam } \\
\text { positivamente com os } \\
\text { seus respectivos } \\
\text { constructos. }\end{array}$ & Valores acima de 0,5 & \\
\hline \multirow{3}{*}{ 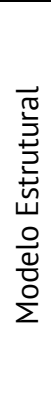 } & $\begin{array}{l}\text { Estimativas dos } \\
\text { coeficientes }\end{array}$ & $\begin{array}{l}\text { Avaliar a significância } \\
\text { dos coeficientes e das } \\
\text { regressões endógenas } \\
\text { (teste } t \text { ). }\end{array}$ & $\begin{array}{l}\text { p-valor significante } \\
\text { em até } 10 \%\end{array}$ & \multirow{3}{*}{ Sanchez (2013) } \\
\hline & $\mathrm{R}^{2}$ & $\begin{array}{l}\text { Avaliar o poder } \\
\text { explicativo das } \\
\text { variáveis exógenas para } \\
\text { as endógenas. }\end{array}$ & \multirow[t]{2}{*}{ Não há. } & \\
\hline & Goodness-of-Fit & $\begin{array}{l}\text { Verificar o ajustamento } \\
\text { do modelo. }\end{array}$ & & \\
\hline
\end{tabular}

Fonte: Elaborado pelos autores.

Assim, o modelo final de cada constructo foi constituído da seguinte forma: i) Autoeficácia Académica - 6 afirmações; ii) Autoeficácia em Ações Proativas - 7 afirmações; iii) Autoeficácia na Gestão Académica - 4 afirmações; iv) Relações Interpessoais - 6 afirmações; v) Relação Organizacionais - 6 afirmações; vi) Controle - 5 afirmações; vii) Distração e Recusa - 3 afirmações; viii) Suporte Social - 4 afirmações; ix) Retraimento - 4 afirmações; $x$ ) Conversão - 3 afirmações; e xi) Aditividade - 3 afirmações. Ressalta-se que a Conversão e a Aditividade alcançaram indicadores satisfatórios após a formação de constructos individuais. 
Na análise da mediação foram utilizados os pressupostos de passos de caminho explicitados por Baron e Kenny (1986), sendo: (A) a variável independente afeta significantemente a variável mediadora; (B) a variável mediadora afeta significantemente a variável dependente; e (C) quando há presença da variável mediadora, a relação anterior da variável independente com a dependente não é mais significante, havendo mediação total quando o coeficiente relacional for zero.

\section{RESULTADOS}

\subsection{MODELO DE MENSURAÇÃO}

Inicialmente, foi analisada a qualidade do modelo de mensuração por meio de indicadores individuais e da validade convergente, com o intuito de verificar a consistência interna dos constructos (Sanchez, 2013) conforme Tabela 2.

Tabela 2

Modelo de mensuração e estatísticas descritivas

\begin{tabular}{ccccccc}
\hline Variáveis & $\begin{array}{c}\text { Alpha de } \\
\text { Cronbach }\end{array}$ & $\begin{array}{c}\text { DG. } \\
\text { rho }\end{array}$ & $\begin{array}{c}\mathbf{1}^{\circ} \\
\text { Autovalor }\end{array}$ & $\begin{array}{c}\mathbf{2}^{\circ} \\
\text { Autovalor }\end{array}$ & $\begin{array}{c}\text { Índ. } \\
\text { Redundância }\end{array}$ & VME \\
\hline $\begin{array}{c}\text { Autoeficácia } \\
\text { Acadêmica }\end{array}$ & 0.845 & 0.886 & 3.40 & 0.741 & 0.000 & 0.566 \\
\hline $\begin{array}{c}\text { Autoeficácia em } \\
\text { ações Proativas }\end{array}$ & 0.860 & 0.893 & 3.81 & 0.874 & 0.000 & 0.542 \\
\hline $\begin{array}{c}\text { Autoeficácia na } \\
\text { Gestão Acadêmica }\end{array}$ & 0.831 & 0.888 & 2.66 & 0.787 & 0.000 & 0.663 \\
\hline $\begin{array}{c}\text { Relações } \\
\text { Interpessoais }\end{array}$ & 0.901 & 0.923 & 4.42 & 0.714 & 0.157 & 0.641 \\
\hline $\begin{array}{c}\text { Relações } \\
\text { Organizacionais }\end{array}$ & 0.888 & 0.915 & 3.85 & 0.974 & 0.052 & 0.519 \\
\hline Controle & 0.832 & 0.882 & 3.00 & 0.648 & 0.155 & 0.599 \\
\hline $\begin{array}{c}\text { Distração ou } \\
\text { Recusa }\end{array}$ & 0.452 & 0.731 & 1.45 & 0.900 & 0.049 & 0.469 \\
\hline Suporte Social & 0.720 & 0.827 & 2.19 & 0.813 & 0.032 & 0.540 \\
\hline Retraimento & 0.714 & 0.824 & 2.17 & 0.808 & 0.021 & 0.533 \\
\hline Conversão & 0.467 & 0.738 & 1.46 & 0.895 & 0.057 & 0.481 \\
\hline Aditividade & 0.799 & 0.882 & 2.14 & 0.564 & 0.072 & 0.652 \\
\hline
\end{tabular}

Nota: 1 =Autoeficácia Académica; 2 = Autoeficácia em ações

Proativas; 3 = Autoeficácia na Gestão Académica; 4 = Relações Interpessoais; 5 = Relações Organizacionais; 6 = Controle; 7 = Distração ou Recusa; 8 = Suporte Social; 9 = Retraimento; $10=$ Conversão; 11 = Aditividade.

Fonte: Dados da pesquisa.

Os indicadores dos constructos apresentaram maioritariamente valores satisfatórios. Somente para a Distração ou Recusa (VME $=0,469$ ) e para Conversão (VME $=0,481$ ) foram identificadas VMEs próximas ao recomendado. Optou-se por manter tais variáveis latentes, na medida em que Hair et al. (2014) expõem que VMEs abaixo de 0,50 podem ser aceitáveis devido à relevância do constructo para o modelo teórico proposto e da proximidade com o parâmetro definido. 
A validade discriminante ocorreu por meio das crossloadings, conforme representado na Tabela 3 .

Tabela 3

Validade Discriminante - Matriz Crossloadings

\begin{tabular}{|c|c|c|c|c|c|c|c|c|c|c|c|}
\hline Variáveis & 1 & 2 & 3 & 4 & 5 & 6 & 7 & 8 & 9 & 10 & 11 \\
\hline \multirow{6}{*}{ 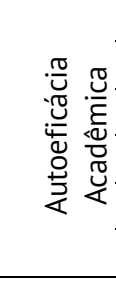 } & 0,784 & 0,378 & 0,539 & 0,339 & 0,249 & 0,303 & 0,160 & 0,072 & $-0,188$ & 0,180 & $-0,09$ \\
\hline & 0,689 & 0,496 & 0,493 & 0,325 & 0,239 & 0,354 & 0,163 & 0,147 & $-0,040$ & 0,194 & $-0,03$ \\
\hline & 0,790 & 0,473 & 0,521 & 0,340 & 0,166 & 0,324 & 0,217 & 0,109 & $-0,065$ & 0,199 & $-0,086$ \\
\hline & 0,817 & 0,474 & 0,508 & 0,424 & 0,243 & 0,395 & 0,265 & 0,197 & $-0,106$ & 0,238 & $-0,167$ \\
\hline & 0,641 & 0,505 & 0,344 & 0,281 & 0,153 & 0,289 & 0,1 & 0,094 & $-0,1$ & 0,101 & $-0,013$ \\
\hline & 0,777 & 0,5 & 0 , & 0,409 & 03 & 0,353 & 0 & 3 & -0 & 68 & 75 \\
\hline \multirow{7}{*}{ 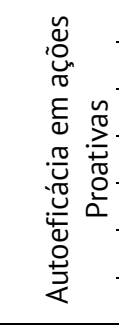 } & נט, 0, & 0,7 & 0 & 0,287 & 0 & 93 & 0 & & 77 & 17 & $-0,053$ \\
\hline & 0,457 & 0,685 & 0,403 & 0,289 & 0,052 & 0,146 & 0 & 75 & $-0,115$ & 0,079 & 82 \\
\hline & 0,445 & 0,802 & 0,354 & 0,268 & 0,100 & 0,167 & 0,110 & 0,185 & $-0,064$ & 0,118 & $-0,054$ \\
\hline & 0,557 & 0,776 & 0,419 & 0,303 & 0,161 & 0,240 & 0,098 & 0,098 & $-0,109$ & 0,133 & $-0,076$ \\
\hline & 0,399 & 0,756 & 0,416 & 0,311 & 0,150 & 0,155 & 0,089 & 0,031 & $-0,085$ & 0,068 & $-0,149$ \\
\hline & 0,354 & 0,6 & 0,313 & 0,151 & 0,230 & 0,137 & 0 & 27 & 34 & 11 & 003 \\
\hline & 0,398 & 0,744 & 0,427 & 0,338 & 0,221 & 0,188 & 0,082 & 30 & 2 & 03 & 31 \\
\hline \multirow{4}{*}{ 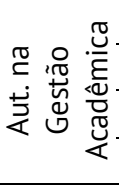 } & 0,570 & 0,542 & 0,773 & 0,342 & 0 , & 0,240 & 0, & 3 & $-c$ & 0,092 & -0 \\
\hline & 0,550 & 0,554 & 0,775 & 0,332 & 0,182 & 0,294 & 0,049 & 0,162 & $-0,068$ & 0,131 & $-0,168$ \\
\hline & 0,521 & 0,332 & 0,835 & 0,292 & 0,213 & 0,287 & 0,097 & 0,134 & $-0,1$ & 0,212 & $-0,250$ \\
\hline & 0,534 & 0,393 & 0,870 & 0,330 & 0,198 & 0,336 & 0,125 & 0,160 & $-0,119$ & 0,252 & $-0,197$ \\
\hline \multirow{6}{*}{ 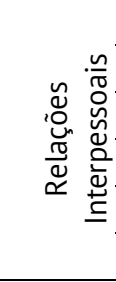 } & 0,468 & 0,286 & 0,353 & 0,758 & 0,303 & 0,345 & 0 & 75 & 06 & 08 & 55 \\
\hline & 0,433 & 0,244 & 0,323 & 0,772 & 0,403 & 0,348 & 0,244 & 0,138 & $-0,008$ & 0,203 & $-0,050$ \\
\hline & 0,407 & 0,357 & 0,341 & 0,819 & 0,432 & 0,232 & 0,109 & 0,1 & 0 & 0,152 & $-0,029$ \\
\hline & 0,307 & 0,301 & 0,289 & 0,826 & 0,568 & 0,228 & 0,213 & 0,214 & 0,070 & 0,208 & 0,021 \\
\hline & 0,294 & 0,316 & 0,267 & 0,799 & 0,547 & 0,228 & 0,104 & 0,190 & 0,025 & 0,175 & $-0,022$ \\
\hline & 0,352 & 0,344 & 0,311 & 0,827 & 0,568 & 0,261 & 0,210 & 0 & 15 & 81 & 008 \\
\hline \multirow{7}{*}{ 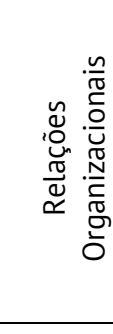 } & 0,193 & 0,218 & 0,165 & 0,472 & 0,750 & 0,232 & 0,107 & 0,128 & 15 & 18 & 0,090 \\
\hline & 0,164 & 0,114 & 0,192 & 0,465 & 0,699 & 0,201 & 0,150 & 0,124 & 50 & 0,121 & 0,069 \\
\hline & 0,252 & 0,123 & 0,144 & 0,429 & 0,828 & 0,245 & 0,178 & 0,150 & 0,097 & 0,274 & 0,084 \\
\hline & 0,205 & 0,147 & 0,164 & 0,442 & 0,726 & 0,272 & 0,184 & 0,105 & 0,023 & 0,212 & 0,080 \\
\hline & 0,185 & 0,175 & 0,155 & 0,492 & 0,813 & 0,236 & 0,121 & 0,156 & 0,124 & 0,167 & 0,111 \\
\hline & 0,261 & 0,168 & 0,178 & 0,511 & 0,892 & 0,267 & 0,213 & 0,117 & 0,065 & 0,239 & 0,105 \\
\hline & 0,272 & 0,238 & 0,224 & 0,450 & 0,832 & 0,369 & 0,151 & 0,236 & 0,048 & 0,337 & 0,073 \\
\hline \multirow{5}{*}{$\begin{array}{l}\frac{0}{0} \\
\text { 는 } \\
\text { ป }\end{array}$} & 0,339 & 0,247 & 0,276 & 0,238 & 0,233 & 0,755 & 0,271 & 0,205 & $-0,223$ & 0,447 & $-0,020$ \\
\hline & 0,378 & 0,227 & 0,191 & 0,272 & 0,321 & 0,812 & 0,227 & 0,130 & $-0,112$ & 0,384 & $-0,107$ \\
\hline & 0,381 & 0,190 & 0,357 & 0,277 & 0,236 & 0,816 & 0,236 & 0,221 & $-0,143$ & 0,419 & $-0,134$ \\
\hline & 0,269 & 0,176 & 0,250 & 0,259 & 0,227 & 0,720 & 0,160 & 0,093 & $-0,163$ & 0,288 & $-0,219$ \\
\hline & 0,365 & 0,173 & 0,304 & 0,292 & 0,275 & 0,764 & 0,147 & 0,225 & $-0,149$ & 0,341 & $-0,098$ \\
\hline \multirow{3}{*}{ 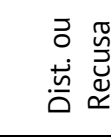 } & 0,206 & 0,090 & 0,093 & 0,184 & 0,195 & 0,255 & 0,737 & 0,181 & 0,107 & 0,164 & 0,063 \\
\hline & 0,160 & 0,053 & 0,034 & 0,137 & 0,131 & 0,094 & 0,663 & 0,135 & 0,121 & 0,111 & 0,058 \\
\hline & 0,159 & 0,110 & 0,050 & 0,162 & 0,062 & 0,176 & 0,650 & 0,092 & $-0,111$ & 0,162 & 0,045 \\
\hline \multirow{4}{*}{$\begin{array}{l}\frac{ \pm}{ \pm} \\
\frac{\pi}{\Delta} \\
\frac{0}{2} \\
\sim \\
\sim\end{array}$} & 0,203 & 0,132 & 0,161 & 0,190 & 0,158 & 0,125 & 0,221 & 0,810 & 0,177 & 0,230 & 0,050 \\
\hline & 0,059 & 0,064 & 0,100 & 0,145 & 0,026 & 0,112 & 0,073 & 0,584 & 0,102 & 0,163 & $-0,056$ \\
\hline & 0,076 & 0,097 & 0,106 & 0,095 & 0,097 & 0,185 & 0,190 & 0,738 & 0,091 & 0,321 & 0,062 \\
\hline & 0,097 & 0,132 & 0,157 & 0,114 & 0,214 & 0,253 & 0,097 & 0,785 & 0,091 & 0,370 & $-0,010$ \\
\hline \multirow{4}{*}{ 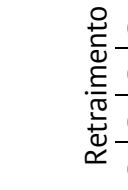 } & $-0,136$ & $-0,061$ & $-0,093$ & 0,054 & 0,019 & $-0,101$ & 0,100 & 0,208 & 0,686 & 0,048 & 0,218 \\
\hline & $-0,060$ & $-0,077$ & 0,013 & 0,026 & 0,049 & $-0,138$ & 0,011 & 0,237 & 0,687 & 0,072 & 0,211 \\
\hline & $-0,038$ & $-0,057$ & $-0,091$ & $-0,013$ & 0,019 & $-0,198$ & 0,071 & $-0,075$ & 0,667 & $-0,034$ & 0,151 \\
\hline & $-0,104$ & $-0,101$ & $-0,169$ & 0,000 & 0,104 & $-0,175$ & 0,014 & 0,086 & 0,843 & $-0,006$ & 0,240 \\
\hline
\end{tabular}




\begin{tabular}{|c|c|c|c|c|c|c|c|c|c|c|c|c|}
\hline \multirow{3}{*}{ 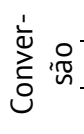 } & $\mathrm{C} 26$ & 0,094 & 0,114 & 0,092 & 0,116 & 0,161 & 0,194 & 0,120 & 0,333 & $-0,038$ & 0,616 & 0,095 \\
\hline & $\mathrm{C} 27$ & 0,244 & 0,133 & 0,268 & 0,192 & 0,244 & 0,530 & 0,178 & 0,270 & $-0,087$ & 0,882 & $-0,064$ \\
\hline & $\mathrm{C} 28$ & 0,135 & 0,037 & 0,005 & 0,124 & 0,206 & 0,168 & 0,154 & 0,199 & 0,304 & 0,535 & 0,214 \\
\hline \multirow{3}{*}{ 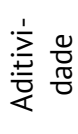 } & $\mathrm{C} 30$ & $-0,144$ & $-0,128$ & $-0,282$ & $-0,072$ & 0,117 & $-0,132$ & 0,059 & $-0,007$ & 0,280 & 0,042 & 0,939 \\
\hline & C31 & $-0,118$ & $-0,117$ & $-0,217$ & 0,028 & 0,080 & $-0,128$ & 0,098 & 0,037 & 0,276 & 0,065 & 0,888 \\
\hline & C32 & $-0,001$ & $-0,010$ & $-0,099$ & 0,057 & 0,051 & $-0,131$ & 0,040 & 0,144 & 0,292 & 0,076 & 0,602 \\
\hline
\end{tabular}

Nota: 1 =Autoeficácia Académica; 2 = Autoeficácia em ações

Proativas; 3 = Autoeficácia na Gestão Académica; 4 = Relações

Interpessoais; 5 = Relações Organizacionais; 6 = Controle; $7=$

Distração ou Recusa; 8 = Suporte Social; 9 = Retraimento; 10 =

Conversão; 11 = Aditividade.

Fonte: Dados da pesquisa.

A carga mínima dos constructos associados revelou-se maior que as cargas cruzadas dos demais constructos, e com valores acima ou próximos a 0,50 , na sua maioria. Perfazendo a qualidade do modelo estrutural, seguiu-se para verificação da hipótese de pesquisa.

\subsection{HIPÓTESE DE PESQUISA}

A avaliação da hipótese de pesquisa é direcionada pelas condições A, B e C de Baron e Kenny (1986), avaliadas a partir dos indicadores do modelo estrutural. $\mathrm{Na}$ Tabela 4 são expostos os resultados obtidos para as condições A e B.

Tabela 4

Avaliação dos Caminhos - Condições A e B

\begin{tabular}{|c|c|c|c|c|}
\hline Condições & Caminho & Coeficiente & p-valor & Decisão \\
\hline \multirow{6}{*}{ (A) } & Aeacad > Organiz & 0,325 & $<0,001$ & \multirow{6}{*}{$\begin{array}{l}\text { Condição } \\
\text { Atendida }\end{array}$} \\
\hline & Aeproat > Organiz & 0,119 & $<0,001$ & \\
\hline & Aegest > Organiz & 0,114 & $<0,001$ & \\
\hline & Aeacad > Interpe & 0,336 & $<0,001$ & \\
\hline & Aeproat > Interpe & 0,034 & $<0,001$ & \\
\hline & Aegest > Interpe & 0,222 & $<0,001$ & \\
\hline \multirow{12}{*}{ (B) } & Organiz > Controle & 0,100 & $<0,001$ & \multirow{12}{*}{$\begin{array}{c}\text { Condição } \\
\text { Parcialmente } \\
\text { Atendida }\end{array}$} \\
\hline & Organiz > Distracao & 0,143 & 0,052 & \\
\hline & Organiz > SupSocial & 0,099 & 0,188 & \\
\hline & Organiz > Retraimento & 0,142 & 0,062 & \\
\hline & Organiz > Conversao & 0,035 & 0,629 & \\
\hline & Organiz > Aditividade & 0,061 & $<0,001$ & \\
\hline & Interpe $>$ Controle & 0,133 & $<0,001$ & \\
\hline & Interpe > Distracao & 0,051 & 0,500 & \\
\hline & Interpe > SupSocial & 0,057 & 0,458 & \\
\hline & Interpe > Retraimento & $-0,049$ & 0,528 & \\
\hline & Interpe > Conversao & 0,164 & 0,031 & \\
\hline & Interpe $>$ Aditividade & 0,029 & $<0,001$ & \\
\hline
\end{tabular}

Nota: Aeacad = Autoeficácia Acadêmica; Controle = Controle; Distracao = Distração ou Recusa ; SupSocial = Suporte Social; Retraimento= Retraimento; Conversao = Conversao; Aditividade = Aditividade; Aeproa = Autoeficácia em ações Proativas; Aegest = Autoeficácia na Gestão Acadêmica.

*p $<0,10 ; * * p<0,05 ; * * * p<0,01$.

Fonte: Dados da pesquisa. 
A condição A foi totalmente atendida, visto que a variável independente, consubstanciada nas dimensões da autoeficácia, afeta significantemente as variáveis mediadoras, representadas pelas relações interpessoais e relações organizacionais. As maiores associações ocorreram entre a autoeficácia académica e as relações interpessoais $(r=0,336$; $p$-valor $=0,000)$ e relações organizacionais $(r=0,325$; $p$-valor $=0,000)$, indicando que discentes que buscam aprender os conteúdos de diferentes formas, atendem às exigências do curso de graduação e aplicam os conhecimentos construídos em situações práticas, possuindo níveis mais elevados de satisfação com as relações interpessoais e organizacionais que permeiam o ambiente universitário. A autoeficácia apresenta-se como preditora da satisfação dessas relações. Ao direcionar olhares para este elemento psicológico, em termos de organização das demandas académicas, tem-se a possibilidade de estabelecer relações mais harmoniosas. Ao possuir segurança na sua capacidade de aprender e gerir a vida académica, o discente tende a sentir-se mais autoconfiante e satisfeito com as pessoas e com a universidade. Esses resultados são particularmente importantes na medida em que as modificações ocorridas na vida dos estudantes suscitam a necessidade de estabelecer novos relacionamentos no ensino superior (Byrne et al., 2014; Carlotto et al., 2015) e confirmam a autoeficácia como direcionadora das relações sociais (Crego et al., 2016).

A condição B foi parcialmente atendida, pois nem todas as relações entre a variável mediadora com as dimensões da variável dependente foram significantes. As maiores associações ocorreram entre as relações organizacionais com estratégias de distração e recusa $(r=0,143$; $p$-valor $=0,052)$ e relações interpessoais com estratégias de conversão $(r=0,164$; $p$-valor $=0,031)$. As estratégias de coping de distração e recusa para o contexto universitário são representadas por atitudes de equilíbrio emocional, como ter paciência e agir somente quando a situação permite atitudes adequadas, "levar na desportiva" o enfrentamento de dificuldades académicas e não ter os sentimentos alterados quando as dificuldades surgem. Já as estratégias de conversão referem-se a mudança comportamental do indivíduo, seja em procurar ajuda de profissionais, modificar a forma de agir em função dos problemas ou traçar planos de ação e aplicá-los a fim de contornar a situação vivenciada.

Nesse sentido, as relações organizacionais em termos de apoio e satisfação com os setores da instituição de ensino, e com os colegas e professores, auxilia na consolidação de posturas comportamentais estáveis nos discentes, possibilitando a superação de dificuldades que venham a ocorrer. As relações organizacionais são corporizadas na satisfação com os recursos e equipamentos disponibilizados pela organização, acervo da biblioteca, espaços de estudo, conforto das instalações, entre outros elementos que apoiam o progresso académico e podem interferir na forma com que os problemas académicos são enfrentados.

0 facto de as relações interpessoais terem apresentado maior associação com as estratégias de coping de conversão, encontra respaldo na constatação de que estas atitudes de enfrentamento são caracterizadas por interações com terceiros - como pedir conselhos a professores, psicólogos e médicos - sobre como lidar com as dificuldades encontradas. Logo, o suporte social apresenta-se como propulsor do comportamento do indivíduo perante 
as adversidades que permeiam o meio académico, pois, ao sentir-se acolhido e satisfeito com as relações estabelecidas na universidade, o discente tende a recorrer ao apoio interpessoal para superar as suas dificuldades (Oliveira et al., 2014; Polydoro \& Guerreiro-Casanova, 2010).

Com intuito de verificar a condição C, foi elaborada a Tabela 5.

Tabela 5

Comparativo entre os modelos - Modelo sem Mediação e Modelo com

Mediação considerando as Relações Interpessoais e Organizacionais -

Condição C

\begin{tabular}{|c|c|c|c|c|c|c|c|c|c|}
\hline & \multirow{3}{*}{ Hipótese } & \multirow{3}{*}{\begin{tabular}{|c|}
$\begin{array}{c}\text { Modelo } \\
\text { sem Med. }\end{array}$ \\
Efeito \\
Coef. \\
\end{tabular}} & \multicolumn{6}{|c|}{ Modelo com Mediação considerando Comportamento Acadêmico } & \multirow{3}{*}{ Decisão } \\
\hline & & & \multicolumn{2}{|c|}{ Efeito Direto } & \multicolumn{2}{|c|}{ Efeito Indireto } & \multirow{2}{*}{\begin{tabular}{|c|} 
Efeito Total \\
Coef. \\
\end{tabular}} & \multirow{2}{*}{\begin{tabular}{|c|}
$\begin{array}{c}\text { Efeito } \\
\text { Med. }\end{array}$ \\
$\%$ \\
\end{tabular}} & \\
\hline & & & Coef. & $\%^{* * * *}$ & Coef. & $\%$ & & & \\
\hline \multirow{18}{*}{$\mathrm{H} 1$} & Aeacad > Controle & $0,405^{* * *}$ & $0,328^{* * *}$ & 80,99 & 0,077 & 19,01 & $0,405^{* *}$ & $\begin{array}{c}19,01 \\
\%\end{array}$ & \multirow{5}{*}{ 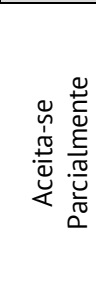 } \\
\hline & Aeacad > Distracao & $0,364^{* * *}$ & $0,303^{* * *}$ & 82,79 & 0,063 & 17,21 & $0,367^{* *}$ & $\begin{array}{l}17,17 \\
\%\end{array}$ & \\
\hline & Aeacad > SupSocial & 0,050 & $-0,006$ & $-13,33$ & 0,051 & 113,33 & 0,045 & \multirow{3}{*}{ NO } & \\
\hline & $\begin{array}{l}\text { Aeacad > } \\
\text { Retraimento }\end{array}$ & $-0,043$ & $-0,070$ & 170,73 & 0,029 & $-70,73$ & $-0,041$ & & \\
\hline & Aeacad > Conversao & $0,174^{* *}$ & 0,119 & 64,32 & 0,066 & 35,68 & 0,186 & & \\
\hline & \begin{tabular}{|l} 
Aeacad $>$ \\
Aditividade
\end{tabular} & $0,076^{* * *}$ & $0,043^{* * *}$ & 59,72 & 0,029 & 40,28 & 0,072 & & \\
\hline & Aeproa > Controle & $-0,058^{* * *}$ & $-0,075^{* * *}$ & 127,12 & 0,016 & $-27,12$ & $-0,058$ & & \\
\hline & Aeproa > Distracao & $-0,027^{* * *}$ & $-0,045$ & 166,67 & 0,018 & $-66,67$ & $-0,026$ & & \\
\hline & Aeproa > SupSocial & 0,060 & 0,046 & 77,97 & 0,013 & 22,03 & 0,060 & & \\
\hline & \begin{tabular}{|l} 
Aeproa > \\
Retraimento \\
\end{tabular} & $-0,022$ & $-0,046$ & 148,39 & 0,015 & $-48,39$ & $-0,031$ & & \\
\hline & Aeproa > Conversao & $-0,037$ & $-0,042$ & 127,27 & 0,009 & $-27,27$ & $-0,032$ & & \\
\hline & $\begin{array}{l}\text { Aeproa > } \\
\text { Aditividade }\end{array}$ & $-0,006^{* * *}$ & $-0,014^{* * *}$ & 233,33 & 0,008 & $-133,33$ & $-0,006$ & & \\
\hline & Aegest $>$ Controle & $0,124^{* * *}$ & $0,080^{* * *}$ & 66,12 & 0,041 & 33,88 & 0,121 & & \\
\hline & Aegest > Distracao & $-0,131^{* * *}$ & $-0,165^{* *}$ & 119,57 & 0,027 & $-19,57$ & $-0,137$ & & \\
\hline & Aegest > SupSocial & 0,118 & 0,097 & 80,17 & 0,024 & 19,83 & 0,121 & & \\
\hline & \begin{tabular}{|l|} 
Aegest > \\
Retraimento \\
\end{tabular} & $-0,105$ & $-0,097$ & 105,43 & 0,005 & $-5,43$ & $-0,092$ & & \\
\hline & Aegest > Conversao & $0,142^{*}$ & 0,073 & 64,60 & 0,040 & 35,40 & 0,114 & & \\
\hline & \begin{tabular}{|l|} 
Aegest $>$ \\
Aditividade
\end{tabular} & $-0,315^{* * *}$ & $-0,337^{* * *}$ & 104,01 & 0,013 & $-4,01$ & $-0,324$ & & \\
\hline \multicolumn{3}{|c|}{ Construto } & & & \multicolumn{2}{|c|}{$\begin{array}{c}\mathbf{R}^{2} \text { - Modelo sem } \\
\text { Mediação }\end{array}$} & \multicolumn{3}{|c|}{$\mathrm{R}^{2}$ - Modelo com Mediação } \\
\hline \multicolumn{3}{|c|}{ Relações Organizacionais } & & & & & \multicolumn{3}{|c|}{$0,246^{* *}$} \\
\hline \multicolumn{3}{|c|}{ Relações Interpessoais } & & & & & \multicolumn{3}{|c|}{$0,285^{* *}$} \\
\hline \multirow{6}{*}{ 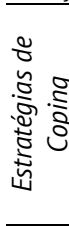 } & \multicolumn{2}{|l|}{ Controle } & & & \multicolumn{2}{|c|}{$0,212^{* *}$} & \multicolumn{3}{|c|}{$0,241^{* *}$} \\
\hline & \multicolumn{2}{|l|}{ Distração } & & & \multicolumn{2}{|c|}{$0,078^{* *}$} & \multicolumn{3}{|c|}{$0,102^{* *}$} \\
\hline & \multicolumn{2}{|l|}{ Suporte Social } & & & \multicolumn{2}{|c|}{$0,039^{* *}$} & \multicolumn{3}{|c|}{$0,053^{* *}$} \\
\hline & Retraimento & & & & & $23^{* *}$ & & $0,032^{* *}$ & \\
\hline & Conversação & & & & & $71^{* *}$ & & $0,090^{* *}$ & \\
\hline & Aditividade & & & & 0,0 & $75^{* *}$ & & $0,085^{* *}$ & \\
\hline Good & dness-of-Fit & & & & & 16 & & 0,284 & \\
\hline
\end{tabular}

Nota: Aeacad = Autoeficácia Académica; Controle = Controle;

Distracao = Distração ou Recusa ; SupSocial = Suporte Social; Retraimento= Retraimento; Conversao = Conversão; Aditividade = Aditividade; Aeproa = Autoeficácia em ações Proativas; Aegest = Autoeficácia na Gestão Académica; NO = Não apresenta efeito mediador. ${ }^{*} p<.10 ; * * p<.05 ; * * * p<.01 . * * * *$ Proporção em relação ao Efeito Total.

Fonte: Dados da pesquisa. 
A partir dos dados compilados na Tabela 5 foi possível tomar uma decisão a respeito da hipótese de pesquisa. Assim, os resultados ilustram que as relações interpessoais e organizacionais atuam como mediadoras de duas dimensões da relação entre autoeficácia académica e estratégias de coping, facto que permite aceitar parcialmente a hipótese de pesquisa, que defende que as relações interpessoais e organizacionais medeiam a relação entre a autoeficácia e as estratégias de coping dos discentes de Ciências Contábeis.

No contexto relacional, entre autoeficácia académica e estratégias de coping na sua dimensão 'controle', há mediação de 19,01\%. Este resultado evidencia que os relacionamentos desenvolvidos no ambiente universitário, na sua interface interpessoal e organizacional, apresentam-se como prováveis facilitadores da forma como o aluno avalia a sua perceção sobre a confiança na capacidade de aprender, demonstrar e aplicar o conteúdo do curso, e controlar situações problemáticas em termos de confronto e resolução de adversidades no ambiente universitário. Tal resultado, em termos práticos, para os estudantes é positivo, pois Carlotto et al. (2015, p. 182) acreditam que "académicos que utilizam estratégias de enfrentamento relacionadas ao confronto e resolução ativa de problemas tendem a apresentar níveis mais baixos de estresse".

Na pesquisa de Costa e Leal, (2006) a estratégia de coping na dimensão de controle mostra-se como a mais utilizada por alunos de graduação de cinco áreas de conhecimento: Ciências Sociais e Humanas, Economia e Gestão, Educação, Engenharia e Ciências do Ambiente, e Nutrição e Enfermagem. A estratégia de controle apresenta-se eficaz nessa pesquisa, quando relacionada a autoeficácia académica percebida pelos alunos participantes.

À luz da Teoria Social Cognitiva, os resultados reforçam que as crenças de autoeficácia percebida conduzem à adoção de estratégias de coping que melhor se adequem ao comportamento do indivíduo, considerando nesta esfera os relacionamentos interpessoais e organizacionais desenvolvidos no ambiente universitário (Bandura, 1977; Ambiel \& Noronha, 2012). Esta interconexão relacional refere-se a relacionamentos com professores, coordenação, colegas de classe, e até ao compromisso da instituição com a qualidade da formação do seu curso. Concorda-se com Guerreiro-Casanova \& Polydoro (2011, p. 76) que "cabe às instituições de ensino superior conhecer cada vez mais como ocorre o impacto da experiência de graduação nos estudantes". Os resultados desta pesquisa ilustram que os estados relacionais, em termos interpessoais e organizacionais, intensificam positivamente o relacionamento entre a autoeficácia académica e as estratégias de coping na sua dimensão controle.

Adicionalmente, na relação entre autoeficácia académica e estratégia de coping na dimensão distração ou recusa há mediação de 17,17\%. Este resultado ilustra que agir como se o problema não existisse - adotando estratégias de não pensar nos problemas a serem resolvidos, ou desenvolver atividades para se distrair ou "esquecer" o problema (como assistir filmes e séries) - é uma prática presente na vida dos alunos, reconhecendo ainda que essa estratégia é minimizada quando se consideram os relacionamentos interpessoais e organizacionais.

Estratégias evitativas, tais como a distração ou recusa, representam um ponto a ser tratado em termos de experiência vivenciada no ambiente de 
ensino superior, pois esse processo de negação como estratégia pode resultar em elevados níveis de stress, e consequentemente na construção de um ambiente universitário não saudável (Oliveira et al., 2014; Ramos \& Carvalho, 2007). Adicionalmente, a adoção frequente de estratégias de distração ou recusa, alinhada aos elementos de autoeficácia e relacionamentos interpessoais e interorganizacionais, pode culminar num ambiente de não integração académica (Dyson \& Renk, 2006).

Os resultados indicam ainda a relevância de considerar o relacionamento interpessoal e organizacional, percebido pelos alunos das IES, nas pesquisas que abordam as crenças de autoeficácia e estratégias de coping, facto evidenciado na comparação do Goodness-of-Fit do modelo direto (GoF $=0,216)$ com o modelo mediador $(G o F=0,284)$. Reconhecer os elementos de relacionamento interpessoal e organizacional mostrou-se oportuno na investigação, na medida em que são constructos ligados ao processo de mudança referente ao ingresso no ensino superior, e ainda representam elementos pertencentes à interação entre autoeficácia académica e estratégias de coping nas suas dimensões controle, distração ou recusa. Tal constatação constitui uma contribuição para o panorama de estudos sobre crenças de autoeficácia e coping no Brasil.

\section{CONCLUSÕES}

Os resultados revelaram que as crenças de autoeficácia e as estratégias de coping podem ser utilizadas como parâmetros para compreensão do comportamento dos discentes no ambiente socioacadémico. A autoeficácia possui relação positiva com as relações interpessoais e organizacionais estabelecidas no ambiente universitário, em termos de satisfação dos discentes. Níveis mais elevados de autoeficácia colaboram para a construção de um ambiente académico harmonioso e que viabiliza o estabelecimento de relações satisfatórias. Além disso, as relações estabelecidas no ambiente universitário influenciam as estratégias de coping no que diz respeito ao controle, distração, retraimento e aditividade, na dimensão organizacional, e controle, conversão e aditividade para as relações interpessoais.

Nesse sentido, o apoio organizacional e o suporte social, que constituem o contexto académico do discente, fomentam a adoção de estratégias para superação de adversidades de diferentes formas. Os resultados apontam que estabelecer relações interpessoais na universidade está ligado à adoção de estratégias de coping voltadas para a busca de apoio social. A disponibilização de núcleos de apoio estudantil, o incentivo do espírito colaborativo entre os discentes (a partir do convívio extra-aula) e o fomento da afetividade dos docentes são elementos que podem ser propostos com o intuito de maximizar a satisfação com as relações estabelecidas na universidade.

As relações interpessoais e organizacionais mostraram-se mediadoras da autoeficácia académica a partir das dimensões de controle e distração das estratégias de enfrentamento. A confiança na capacidade de superar os problemas académicos por meio de estratégias de distração e de controle das emoções é maximizada a partir do estabelecimento de relações estáveis 
com os colegas de classe, professores e colaboradores da IES, e com a satisfação com a estrutura organizacional da instituição. Esta constatação reforça a relevância de atentar em elementos que transcendem os aspetos cognitivos, mas que englobam a forma com que o discente vislumbra a universidade na qual estuda.

Ao fomentar a satisfação com ambas as dimensões relacionais, o discente tende a minimizar o uso de estratégias de coping de distração e recusa, e passa a enfrentar as adversidades de forma mais direta. Acredita-se que deste modo são minimizadas atitudes de procrastinação na resolução das dificuldades, incentivando-se o delineamento de planos de ações. Estes resultados são importantes, pois contribuem para o amadurecimento do discente e para o desenvolvimento de habilidades de enfrentamento adequadas às situações vivenciadas no ambiente universitário.

Espera-se que estudos futuros aprofundem a análise qualitativa deste tipo de fenómenos.

\section{REFERÊNCIAS}

Ambiel, R. A., \& Noronha, A. P. P. (2012). Escala de Autoeficácia para Escolha Profissional: manual técnico. Casa do Psicólogo.

Bandura, A. (1977). Self-efficacy: Toward a unifying theory of behavioral change. Psychological Review, 84(2), 191-215. https://doi. org/10.1037/0033-295X.84.2.191

Bandura, A. (1982). Self-efficacy mechanism in human agency. American Psychologist, 37(22), 122-147. https://doi.org/10.1037/0003-066X.37.2.122

Bandura, A. (1993). Perceived self-efficacy in cognitive development and functioning. Educational Psychologist, 28(2), 117-148. https://doi.org/10.1207/ s15326985ep2802_3

Bandura, A. (1994). Social cognitive theory and exercise of control over HIV infection. In R. J. DiClemente et al. (Eds.), Preventing AIDS (pp. 25-59). Springer Science Business.

Bandura, A. (1997). Self-Efficacy: The exercise of control. W.H. Freeman.

Barcelos, A. T. D. P. (2010). Autoeficácia e coping em policiais militares. Dissertação de mestrado em Psicologia, Pontifícia Universidade Católica de Goiás.

Baron, R. M., \& Kenny, D. A. (1986). The moderator-mediator variable distinction in social psychological research: Conceptual, strategic, and statistical considerations. Journal of Personality and Social Psychology, 51(6), 1173-1182. https://doi.org/10.1037/0022-3514.51.6.1173

Byrne, M., Flood, B., \& Griffin, J. (2014). Measuring the academic selfefficacy of first-year accounting students. Accounting Education, 23(5), 407-423. https://doi.org/10.1080/09639284.2014.931240

Capelo, R., \& Pocinho, M. (2016). Estratégias de coping: contributos para a diminuição do stresse docente. Psicologia, Saúde \& Doenças, 17(2), 282-294. https://doi.org/http://dx.doi.org/10.15309/16psd170213

Carlotto, R. C., Teixeira, M. A. P., \& Dias, A. C. G. (2015). Adaptação acadêmica e coping em estudantes universitários. Psico-USF, 20(3), 421-432. https://doi.org/http://dx.doi.org/10.1590/1413-82712015200305 
Correia, A. C. da R. (2010). Coping e autoeficácia em pais de crianças e adolescentes com Diabetes Tipo I. Universidade Fernando Pessoa.

Costa, E. S., \& Leal, I. P. (2006). Estratégias de coping em estudantes do Ensino Superior. Análise Psicológica, 2, 189-199.

Crego, A., Carrillo-Diaz, M., Armfield, J. M., \& Romero, M. (2016). Stress and academic performance in Dental Students: The Role of Coping Strategies and Examination-Related Self-Efficacy. Journal of Dental Education, 80(2), 165-172. https://doi.org/ 80/2/165 [pii]

Devonport, T.J., \& Lane, A. M. (2006). Relationships between self-efficacy, coping and student retention. Social Behavior and Personality: An International Journal, 34(2), 127-138. https://doi.org/10.2224/sbp.2006.34.2.127

Duarte, F. D., \& Faria, L. (2016). Papel da motivação e da autoeficácia na escolha da especialidade médica. Psicologia, Educação e Cultura, 20(1), 293-303.

Durso, S. de O. (2015). Características do processo de evasão dos estudantes do Curso de Ciências Contábeis de uma Universidade Pública Brasileira. Dissertação de mestrado em Contabilidade, Universidade Federal de Minas Gerais, Belo Horizonte, MG, Brasil.

Dyson, R., \& Renk, K. (2006). Freshmen adaptation to university life: Depressive symptoms, stress, and coping. Journal of clinical psychology, 62(10), 1231-1244. https://doi.org/10.1002/jclp.20295

Fernandes, V. M. P. (2011). Adaptação académica e auto-eficácia em estudantes universitários do 10 ciclo de estudos. Dissertação de mestrado em Psicologia Clínica e da Saúde, Universidade Fernando Pessoa, Porto, Portugal.

Gloria, C. T., \& Steinhardt, M. A. (2016). Relationships among positive emotions, coping, resilience and mental health. Stress and Health, 32(2), 145-156. https://doi.org/10.1002/smi.2589

Guerreiro-Casanova, D. C., \& Polydoro, S. A.J. (2011). Autoeficácia e integração ao ensino superior: Um estudo com estudantes de primeiro ano. Psicologia: Teoria e Prática -, 13(1), 75-88. https://doi.org/10.1016/j. mstc.2011.03.006

Hair, J. F. J., Hult, G. T. M., Ringle, C., \& Sarstedt, M. (2014). A primer on partial least squares structural equation modeling (PLS-SEM). Long Range Planning (Vol. 46). https://doi.org/10.1016/j.lrp.2013.01.002

Hsieh, P. H., Sullivan, J. R., Sass, D. A., \& Guerra, N. S. (2012). Undergraduate engineering students beliefs, coping strategies, and academic performance: An evaluation of theoretical models. Journal of Experimental Education, 80(2), 196-218. https://doi.org/10.1080/00220973.2011.596853

Lazarus, R. S., \& Folkman, S. (1984). Stress, appraisal, and coping. Springer Publishing Company.

Loricchio, T. M. B., \& Leite,J. R. (2012). Estresse, ansiedade, crenças de autoeficácia e o desempenho dos bacharéis em Direiro. Avaliação Psicológica, 11(1), 37-47.

Matos, P. A. V. C. de. (2014). Síndrome do impostor e auto-eficácia de minorias sociais: Alunos de Contabilidade e Administração. Dissertação - Programa de Pós-Graduação em Contabilidade - Universidade de São Paulo. https://doi. org/10.11606/D.12.2014.tde-07012015-175044 
Moreira, T. D. C., Ambiel, R. A. M., \& Nunes, M. F. O. (2018). Career Choice Self-Efficacy Source Scale: Development and Initial Psychometric Studies. Trends in Psychology, 26(1), 47-60. https://doi.org/10.9788/tp2018.1-03pt

Oliveira, C. T. de, Carlotto, R. C., \& Dias, S. J. L. V. A. C. G. (2014). Adaptação acadêmica e coping em estudantes universitários Brasileiros : Uma Revisão de Literatura. Revista Brasileira de Orientação Profissional, 15(2), 177-186.

Pajares, F. (1996). Self-efficacy beliefs in achievement settings. Review of Educational Research, 66(4), 543-578. https://doi.org/10.3102/00346543066004543

Peleias, I. R., Guimarães, E. R., Chan, B. L., \& Carlotto, M. S. (2017). A Síndrome de Burnout em estudantes de Ciências Contábeis de IES Privadas: Pesquisa na Cidade de São Paulo. Revista de Educação e Pesquisa em Contabilidade, 11(1), 30-51.

Pocinho, M., \& Capelo, M. R. (2009). Vulnerabilidade ao stress, estratégias de coping e autoeficácia em professores portugueses. Educação e Pesquisa, 35(2), 351-367.

Polydoro, S. A. J., \& Guerreiro-Casanova, D. C. (2010). Escala de autoeficácia na formação superior: Construção e estudo de validação. Avaliação Psicológica, 9(2), 267-278.

Ramos, S. I. V., \& Carvalho, A. J. R. (2007). Nível de stress e estratégias de coping dos estudantes do $1^{\circ}$ ano do ensino universitário de Coimbra. Psicologia.com. pt,1-17.

Sanchez, G. (2013). PLS path modeling with R. Berkeley: Trowchez Editions. Retrieved from http://www.gastonsanchez.com/PLS Path Modeling with R.pdf\%0Ai

Satchakova, L. (2018). The role of self-efficacy factors, individual characteristics and WIL participation on accounting near-graduate students' employment outcomes By. Victoria University.

Schleich, A. L. R., Polydoro, S. A. J., \& Santos, A. A. A. dos (2006). Escala de satisfação com a experiência acadêmica de estudantes do Ensino Superior. Avaliação Psicológica, 5(1), 11-20.

Silva, J. E. de A., Silveira, C. da, \& Matos, C. V. G. de (2015). Níveis de estresse dos contabilistas atuantes em escritórios contábeis de Uberlândia. Revista Mineira de Contabilidade, 16(3), 5-16.

Silva, T. D. (2017). O estresse e sua relação com o desempenho acadêmico: um estudo com graduandos de Ciências Contábeis e Administração. Universidade Federal de Uberlândia. https://doi.org/10.14393/ufu.di.2018.44

Teixeira, M. A. P., Dias, A. C. G., Wottrich, S. H., \& Oliveira, A. M. (2008). Adaptação à universidade em jovens calouros. Revista Semestral Da Associação Brasileira de Psicologia Escolar e Educacional (ABRAPEE), 12(1), 185-202. https://doi. org/10.1590/S1413-85572008000100013

Tepper, R., \& Yourstone, S. A. (2018). Beyond ACT \& GPA: SelfEfficacy as a Non-Cognitive Predictor of Academic Success. International Journal of Accounting \& Information Management, 26(1), 171-186. https://doi. org/10.1108/09574090910954864 
Informação dos autores:

i Universidade Federal do Paraná, Brasil. https: //orcid.org/0000-0002-3704-933X

ii Universidade Federal do Paraná, Brasil. https://orcid.org/ 0000-0001-7627-4815

iii Universidade Federal do Paraná, Brasil. https://orcid.org/ 0000-0003-3589-9389

Toda a correspondência relativa a este artigo deve ser enviada para:

Alison Martins Meurer

Programa de Pós-Graduação em Contabilidade - Mestrado

e Doutorado - UFPR

Setor de Ciências Sociais Aplicadas

Av. Prefeito Lothário Meissner, 632 - UFPR

CEP: 80210-170 - Curitiba, Paraná, Brasil

alisonmmeurer@gmail.com

Recebido em 20 de agosto de 2019

Aceite para publicação em 15 de maio 2020 


\title{
Self-effectiveness, coping strategies and the effects of interpersonal and organizational relationships of Accounting Sciences' students
}

\begin{abstract}
This research seeks to verify the influence of self-efficacy on coping strategies mediated by interpersonal and organizational relationships established by students of Accounting Sciences. This descriptive research with a quantitative approach has as a sample 311 students from Public and Private Higher Education Institutions, located in the state of Paraná (Brasil), and matriculated in the year 2018. From the Structural Equation Modelling (MEE) technique it was possible to verify that interpersonal and organizational relationships act as mediators of academic self-efficacy with coping strategies aimed at refusal and distraction. The results illustrate that recognizing the mediating position of the interpersonal and organizational relationship between self-efficacy and coping strategies is timely, as they are constructs linked to the process of overcoming adversities experienced in higher education. The findings indicate that, by fostering satisfactory interpersonal and organizational relationships, the student's ability to address problems more directly is maximized. This ability becomes important as it contributes to the student's maturity and to the development of coping skills appropriate to the situations experienced in the socio-academic environment.
\end{abstract}

Keywords: Self-efficacy; Coping strategies; Students of accounting; Accounting education. 


\section{Autoeficacia, estrategias de afrontamiento y efectos de las relaciones interpersonales y organizacionales de estudiantes de Ciencias Contables}

\section{RESUMEN}

Esta investigación busca verificar la influencia de la autoeficacia en las estrategias de afrontamiento mediadas por las relaciones interpersonales y organizativas establecidas por los estudiantes de Ciencias Contables. Para ello, la investigación descriptiva con enfoque cuantitativo tiene como muestra a 311 estudiantes de instituciones públicas y privadas de educación superior, ubicadas en el estado de Paraná (Brasil), y matriculados en el año 2018. Desde la técnica del modelado de ecuaciones estructurales (MEE) fue posible verificar que las relaciones interpersonales y organizativas actúen como mediadores de la autoeficacia académica con estrategias de afrontamiento dirigidas al rechazo y la distracción. Estos resultados ilustran que el reconocimiento de la posición mediadora de la relación interpersonal y organizativa entre la autoeficacia y las estrategias de afrontamiento es oportuno, ya que son construcciones vinculadas al proceso de superar las adversidades experimentadas en la educación superior. Los resultados indican que, al fomentar relaciones interpersonales y organizativas satisfactorias, se maximiza la capacidad del estudiante para abordar los problemas de manera más directa. Esta capacidad se vuelve importante ya que contribuye a la madurez del estudiante y al desarrollo de habilidades de afrontamiento adecuadas a las situaciones experimentadas en el entorno socio-académico.

Palabras clave: Autoeficacia; Estrategias de afrontamiento; Estudiantes de contabilidad; Educación contable. 